\title{
EL JUICIO REFLEXIVO EN LA ÉTICA KANTIANA
}

DULCE MaRÍa GRANJA

DEPARTAMENTO DE FILOSOFÍA

UNIVERSIDAD AUTÓNOMA METROPOLITANA

"Dieser kann nun nichts anders als das Subjekt aller möglichen Zwecke selbst sein, weil dieses zugleich das Subjekt eines möglichen schlechterdings guten Willens ist; denn dieser kann, ohne Widerspruch, keinem andern Gegenstande nachgesetzt werden." (Ak., IV, 437.)

\section{Introducción: el concepto de finalidad y el papel del juicio reflexivo}

Los cambios que Kant introduce en el pensamiento filosófico moderno no sólo afectan el terreno especulativo, sino también el ámbito de la acción humana. En estos dos planos Kant buscó, respectivamente, la validez objetiva de la ciencia y la moral. Para Kant, el carácter objetivo que la moralidad requiere sólo puede ser explicado recurriendo al sujeto, más específicamente, a la autono:nía o libertad de su voluntad. Sobre esta base Kant elabora un modelo de autorreflexión crítica sobre la acción humana de especial importancia en el debate filosófico contemporáneo. En efecto, en primer lugar, Kant eleva ciertos problemas cruciales que hasta entonces se habían abordado en direcciones contrapuestas, a un grado superior de elucidación y reflexión. Además, para él la acción humana es objeto de una argumentación racional que constituye el fumdamento del principio supremo de la moralidad. Por último, su modelo se destaca por la solidez de sus argumentaciones y la precisión de sus conceptos.

Sin embargo, la ética de Kant suele interpretarse de modo fragmentario, e incluso tales fragmentos no pocas veces adolecen de graves malentendidos. Así, e.g., se ha acusado a Kant de rigorismo; se le ha reprochado que le falta el concepto de praxis; se le achaca imposibilitar la comprensión de la unidad de la acción humana al fundar su ética sobre una dudosa teoría de dos mundos (el moral y el empírico, el de la naturaleza y el de la libertad); se levanta contra él el cargo de proponer un deber moral ahistórico y meramente subjetivo, etc. Yo no podré abordar aquí todas estas quejas y me limitaré a examinar la acusación de "formalismo" porque creo que en ella confluyen, en buena medida, diversos aspectos de los restantes cargos. Los detractores sostienen que la ética de Kant es formalista porque no nos propone la realización de ningún bien, porque desatiende las consecuencias 
de nuestros actos, porque no tiene en cuenta los intereses contrapuestos de los diversos individuos y porque al ser una ética deontológica, i.e., del deber no da cabida a la felicidad humana, de modo que las éticas teleológicas o de fines la aventajan considerablemente.

Creo que muchas de las imputaciones señaladas se debilitan con sólo seguir atentamente la argumentación del propio Kant. En esta argumentación encontramos el concepto crucial de "reflexión" como parte de la actividad mental del sujeto. Por ello el propósito de este trabajo será tratar de reconstruir la argumentación que Kant presenta en torno al juicio reflexivo en la esfera ética para ver en qué medida se puede dar respuesta a las acusaciones antes mencionadas de los detractores de la filosofía kantiana.

Para Kant ${ }^{1}$ las facultades cognitivas superiores de la mente, i.e., el conjunto de capacidades que contribuyen al conocimiento exceptuando a la sensibilidad son tres: 1. el entendimiento o capacidad para el conocimiento de lo universal (las reglas, los principios y las leyes), 2. el juicio o capacidad de pensar lo particular como contenido bajo lo universal y 3 . la razón o capacidad para determinar lo particular mediante lo universal (i.e., deducir a partir de principios).

Como veremos en las siguientes páginas, la facultad del juicio es un eslabón entre el entendimiento y la razón, y la operación lógica del juicio presenta dos formas:

a) El juicio determinante: va de lo general a lo particular. Lo universal (regla, principio o ley) es dado y el juicio hace entrar a un individuo o caso particular en una clase. Esta subsunción o inclusión de lo especial en lo general se hace en función de una regla, principio o ley. Por ello el juicio determinante parte de lo general como lo dado y va a lo particular. $^{2}$

b) El juicio reflexivo o reflexionante: va de lo particular a lo general. Lo particular es dado y sobre él se debe encontrar lo universal. Busca lo general en lo especial. El juicio reflexivo logra, mediante la espontaneidad o actividad mental del sujeto, otorgar un alcance general $\mathrm{e}$

1 Cfr. Ak., Kritik der Urteilskraft, Ak, V, Prefacio, A III-B VI, A VI, B III. Todas las referencias a las obras de Kant pertenecen a la edición clásica de la Real Academia Prusiana de las Ciencias, actualmente Academia Alemana de las Ciencias, indicando el volumen y las páginas correspondientes. La abreviatura "Ak." remite precisamente a Kants gesammelte Schriften, Hrsg. von der Königlich Preussischen und der Deutschen Akademie der Wissenschaften, 29 vols., primeramente G. Reimer y más tarde Walter de Gruyter, Berlín, 1902 ss.

2 Cfr. Ak. IX, Logik, herausgegeben von Gottlob Benjamin Jäsche (nach Vorlesungen) $\S 81$, Lecciones de lógica, segunda parte, cap. III, sec. III. 
independiente de la experiencia a algo que aparece dado a la sensibilidad. ${ }^{3}$

En las dos introduicciones de la Crítica del juicio, Kant afirma que el concepto de finalidad señala la tarea sistemática y la función mediadora propias del juicio reflexivo. ${ }^{4}$ Cuando se afirma que algo tiene sentido finalista, se hace referencia a ciertos fenómenos considerados como un todo y se somete ese todo a un fin. Los fenómenos se pueden constatar empíricamente, constituyendo el dato especial. En cambio, el ordenamiento de la totalidad a un fin es el elemento general que no es dado empíricamente y que el juicio descubre con su propia espontaneidad. Así, en los juicios finalistas, el dato sensible, que es la naturaleza y la afirmación espontánea, que es la libertad, forman una unidad originaria.

Kant recurre reiteradamente al concepto de finalidad en la mayoría de sus obras de filosofía práctica. Así por ejemplo, en la Crítica de la razón práctica, la teoría de los postulados presupone la idea teleológica de una unidad entre el mérito y la felicidad. Por otra parte, la idea normativa de lo bueno incondicional no se restringe a la dimensión de la praxis personal, sino que también es válida en el nivel institucional de la praxis humana del derecho y el Estado. Para él, la legislación propia de la razón sólo se da en el terreno práctico ${ }^{5}$ y comprende no sólo la moralidad, entendida como ética de una persona, sino rambién la justicia política entendida como ética de la convivencia conforme al concepto racional de derecho. Kant considera que la voluntad ética no es indiferente a su plasmación en el mundo social y político y que la meta o el "sentido" de la historia está en ese "reino de los fines" en que, como su nombre lo dice, los seres humanos se considerarían recíprocamente los unos a los otros como fines en sí mismos. Kant caracteriza este reino como una comunidad moral convertible, bajo ciertas condiciones, en una comunidad política real. En la tercera Crítica, ${ }^{6}$ Kant

3 Véase Eisler, Rudolf, Kant Lexikon, "Urteil", "Urteile","Urteilskraft", Georg Olms Verlag, Hildesheim, 1989, pp. 558-568.

4 Para Kant el juicio reflexivo ejerce una función mediadora entre entendimiento y razón, naturaleza y libertad, filosofía teórica y práctica.

5 Recordemos que en las introducciones a la tercera Crítica, Kant divide la filosofía en teórica y práctica. La primera investiga las leyes dictadas por los conceptos del entendimiento puro aplicados a la naturaleza, en tanto que la última investiga las leyes dictadas por los conceptos de la razón pura centrados en la libertad. Así pues, la razón sólo es legisladora en el terreno práctico. Sin embargo, las esferas de naturaleza y libertad, mundo sensible fenoménico y mundo inteligible moral, no pueden ser extrañas una a la otra, puesto que la libertad tiene que expresarse en el mundo sensible. Para conectar mundo natural y mundo moral, conocimiento y acción, es necesario buscar un puente de unión que Kant cree haber encontrado en el juicio reflexivo.

6 Véanse especialmente los $\S \S 83$ y 84. 
aborda el destino de la naturaleza considerada como un sistema teleológico y sostiene que en virtud de una causalidad ideal que fija los objetivos a la "técnica de la naturaleza" surge un mundo donde la naturaleza, como instrumento de la razón, se dirige hacia una finalidad moral. Así, en la idea del universo como creación coinciden la libertad y la felicidad en el marco de una cultura moral.

En las siguientes secciones, intentaremos destacar los conceptos de finalidad y juicio reflexivo en algunas secciones de la Fundamentación de la metafísica de las costumbres y de la segunda Crítica para reconstruir la teoría moral que ahí se nos ofrece a la luz de tales conceptos. Creo que con ello se podrá responder, en alguna medida, a las dificultades señaladas al inicio de este trabajo. Esta reconstrucción me permitirá sostener la tesis central de este trabajo, a saber, que el juicio en torno a la moralidad de nuestras propias acciones es un juicio reflexivo y no un juicio determinante, como podría suponerse. También sobre la base de dicha reconstrucción concluiré que las cuestiones de identidad moral, así como las de educación y evaluación moral de las personas, han de tener en cuenta la perspectiva del juicio reflexivo.

\section{Lo bueno moral y el imperativo categórico}

Kant define el concepto de lo bueno moral distinguiéndolo de todos los otros conceptos de lo bueno. Para él "moralmente bueno" significa "incondicionalmente bueno", i.e., bueno sin ninguna condición restrictiva, bueno en sí y sin otra intencionalidad. Kant empieza su Fundamentación de la metafísica de las costumbres con una frase que hasta la fecha sigue suscitando discusión. En ella afirma que lo único incondicionalmente bueno es la buena voluntad. ${ }^{7}$ Ahora bien, el ser humano no tiene una voluntad que quiera el bien directamente y sin necesidad de verse movido a ello por el deber. Por esto, cuando Kant describe la buena voluntad apelando al concepto de deber, no significa que los términos "deber" y "buena voluntad" tengan el mismo contenido conceptual.

En primer lugar, Kant distingue entre voluntad o razón práctica empíricamente condicionada y voluntad o razón práctica pura. La primera es influida desde fuera por impulsos, necesidades, pasiones sensibles, sensaciones de agrado y desagrado, costumbres, etc. La segunda no es la capacidad de destruir todas estas influencias, sino más bien de obrar según leyes au-

7 Hay también otros lugares, e.g., la Crítica de la razón práctica, $A k$. V, 64, donde afirma que lo bueno incondicional no consiste en un objeto supremo de la voluntad, sino en la misma buena voluntad. 
toimpuestas, suspendiendo así los impulsos naturales en cuanto motivación determinante del obrar y guiándose desde sí misma.

En segundo término, cuando la razón práctica se guía desde sí misma, cabe todavía preguntar cuál es la motivación determinante del obrar según leyes autoimpuestas. Para Kant pueden darse tres posibles respuestas, que incluyen otras tantas clases de motivos racionales, los cuales manifiestan, a su vez, tres grados de racionalidad práctica. Dichos grados no se refieren a la necesidad o rigor, sino más bien al alcance de la necesidad.

El primer grado pertenece a los imperativos técnicos y, el segundo, a los imperativos pragmáticos de la prudencia. En los dos se prescriben acciones necesarias para lograr un fin determinado. Ahora bien, estos imperativos sólo regirán para mí y me consideraré obligada a cumplir sus mandatos en el supuesto de que yo persiga la finalidad a la que ellos apuntan; pero es opcional tener o no tal propósito. Hasta este punto, los imperativos son necesidades prácticas, i.e., normas de acción válidas para todos y que difieren de lo agradable que nace de las sensaciones meramente subjetivas. ${ }^{8}$

El tercer grado pertenece al imperativo categórico o moral en el cual todos los supuestos restrictivos quedan excluidos; aquí el precepto obliga incondicionalmente; por ello, como veremos, es el grado más elevado, no superable, de racionalidad práctica. Un imperativo así se caracterizaría por su validez ilimitada: necesaria y sin excepciones. Esta forma perfecta de racionalidad práctica y obligatoriedad valen como signo y criterio de moralidad.

Antes de pasar a las diversas formulaciones del imperativo categórico que Kant nos ofrece, es conveniente hacer un breve señalamiento en torno a las máximas, puesto que lo que el imperativo categórico ordena se refiere únicamente a lo que Kant designa como "máximas". En efecto, la ética de Kant no es una ética de normas, sino, más bien, una ética de máximas.

Una máxima es un principio subjetivo que comprende varias normas o reglas prácticas y que establece un principio directivo según el cual se orienta globalmente la propia existencia ante las situaciones concretas de la vida. Puesto que las máximas son determinaciones generales de la voluntad, i.e., actividades fundamentales que vinculan las acciones e intenciones concretas confiriéndoles una dirección común, es claro que son esquemas ordenadores que no podrían ser descubiertos empíricamente por un observador externo al sujeto moral. Además, son principios directivos que podrian ser idénticos en varios sujetos y, no obstante, contener bajo sí normas diferentes según sean las circurstancias particulares en las que se halla cada sujeto y las posibilidades con las que cuenta.

${ }^{8}$ Cfr. Fundamentación de la metafísica de las costumbres, Ak., IV, 413. 
Ya desde este punto podemos apreciar la necesidad del juicio reflexivo, sin el cual no se daría lugar a máximas que extrajeran de la acción concreta la línea directiva. En efecto, es el juicio reflexivo el que nos permite considerar la diversidad y las peculiaridades de cada situación y, partiendo de ellas, encontrar los principios generales de las normas. Sin el juicio reflexivo careceríamos de las máximas que nos permiten calificar moralmente a un sujeto, e.g., como magnánimo o vengativo, honrado o deshonesto, respetuoso o egoísta. Sin tales máximas no podríamos evitar que la biografía de una persona se limitara a ser una sucesión ininterminable y caótica de acciones desarticuladas y normas inconexas. Las máximas son como el hilo conductor que nos permite hablar de regularidad y que introduce el concepto de praxis en la ética kantiana. Pero el papel del juicio reflexivo no termina aquí; también está presente cuando examinamos racionalmente la moralidad de las máximas a la luz del imperativo categórico. De ello nos ocuparemos en el siguiente apartado al revisar las diversas formulaciones de dicho imperativo que Kant nos propone.

\section{Las formulaciones del imperativo categórico}

En la Fundamentación. . ${ }^{9}$ Kant sostiene que existen tres maneras de representar el imperativo categórico y que en el fondo son otras tantas fórmulas de una y la misma ley, cada una de las cuales contiene en sí a las otras dos. Estas tres fórmulas se refieren, respectivamente, a la forma, a la materia y a la determinación integral de las máximas. ${ }^{10}$

Considerando que la forma de las máximas consiste en la universalidad, la primera formulación del imperativo categórico diría así: "Obra como si la máxima de tu acción debiera convertirse por tu voluntad en ley general" o bien: "Obra conforme a la máxima que puedas querer que sea ley universal."11 Ésta es la fórmula más citada del imperativo categórico y mejor conocida como "fórmula de la universalización". Yo no la abordaré aquí, pues para mi propósito sólo me interesa destacar que de ella se sigue la idea según la cual la voluntad de todo ser racional es universalmente legisladora. En efecto, según este principio, son rechazadas todas las máximas que no pueden conciliarse con la propia legislación universal de la voluntad. En otras palabras, la afirmación de que la legislación moral alcanza a todos los sujetos equivale a decir que cada uno de esos sujetos es legislador. Así,

9 Véase $A k$, IV, 436.

10 La universalidad nos proporciona la forma de la ley moral; la naturaleza racional o humanidad como fin en sí misma nos da la materia de la ley; y la legislación autónoma en un reino de los fines nos da una determinación completa de las máximas y una totalidad de fines.

11 Cfr. Ak. IV, 421 y 422, respectivamente. 
un imperativo categórico sólo podría ordenar la máxima de una voluntad tal que pueda tenerse a sí misma como universalmente legisladora. Dicha voluntad está sujeta a su propia ley y, tal ley es universal, i.e., vale para todos sin excepción alguna, ni siquiera de quien la emite. De este modo, el principio de la universalidad no es otro que el de la autodeterminación.

Si el deber es un concepto que posee significación y legislación real sobre nuestras acciones, no puede expresarse más que en un imperativo categórico, ${ }^{12}$ i.e., mediante una ley práctica que manda por sí, absolutamente y cuya obediencia es deber. Esto nos lleva al segundo modo de representar el imperativo categórico. En esta segunda fórmula, Kant tiene en cuenta el contenido o materia y arranca de la naturaleza racional como fin en sí misma. En efecto, lo que es fin para todos necesariamente porque es fin en sí mismo, constituye un principio objetivo de la voluntad y, por lo tanto, puede servir de ley práctica universal. El fundamento de este principio es precisamente el que la naturaleza racional existe como fin en sí misma. De este modo la segunda formulación del imperativo categórico dice así: "Obra de tal modo que consideres a la humanidad tanto en tu persona como en la de cualquier otro, siempre como un fin y nunca solamente como un medio."13 Por razones de brevedad me referiré a esta segunda formulación como "fórmula de la humanidad". Esta segunda formulación responde a la pregunta de por qué deberíamos obedecer un imperativo categórico. En tanto que aquí se atiende el contenido o materia de las máximas, ésta formulación representa la ley moral en términos del valor que proporciona la razón o fundamento que motiva a un ser racional a actuar de acuerdo con el imperativo categórico. Esto equivale a decir que esta fórmula nos proporciona el contenido o motivo del deber.

La fórmula de la humanidad conduce a un concepto muy relacionado con ella, i.e., el concepto de "reino de los fines" y a la tercera formulación del imperativo categórico. En esta última fórmula, Kant tiene en cuenta la determinación integral de todas las máximas y se enuncia así: "Todas las máximas, por su propia legislación, deben concordar en un posible reino de los fines como reino de la naturaleza." ${ }^{14}$ Para los propósitos de este trabajo, en que trato de la finalidad de las acciones humanas en la esfera moral y el papel que en ello desempeña el juicio reflexivo, no es necesario abordar

12 Cfr. Ak., IV, 425.

13 Cfr. Ak, IV, 429. Véase también: Korsgaard, Christine, "Kants Formula of Humanity", en Kant Studien, no. 77, 1986, pp. 183-202; Wood, Allen, "Humanity as End in Itself", Proceeding of the Eighth International Kant Congress, 1995, Marquette University Press, Memphis, vol. I, parte 1, pp. 301-319; Watson, Stephen, "Kant on Autonomy, the Ends of Humanity and the Possibility of Morality", en Kant Studien, no. 77, 1986, pp. 165-181.

14 Cfr. Ak, IV, 436. 
la tercera fórmula del imperativo categórico. No obstante que en dicha fórmula el papel del juicio reflexivo es de crucial importancia, ella apunta más bien hacia las doctrinas de filosofía política y filosofía de la historia que Kant nos propone y esto ameritaría un pormenorizado estudio. Ciertamente el proyecto ético kantiano es un proyecto político e histórico, pero esta consideración está fuera de los propósitos del presente trabajo. ${ }^{15}$ Aquí sólo destacaré que por "reino de los fines" se designa el enlace sistemático de distintos seres racionales por leyes objetivas comunes. Si prescindimos de las preferencias personales y de los fines privados de tales seres racionales, tendremos un todo de todos los fines, i.e., un reino de los fines en el cual todos los seres racionales están sujetos a la ley de que cada uno de ellos debe tratarse a sí mismo y a todos los demás "nunca como simple medio y siempre como fin en sí mismo". En este sentido deseo hacer sólo un par de observaciones. En primer lugar, habría que destacar que un ser racional pertenece al reino de los fines como miembro de él cuando es legislador universal y está sujeto a las leyes de tal reino. ${ }^{16}$ En segundo lugar, este reino de los fines, si bien es un ideal, ello no excluye que sea posible por la libertad de la voluntad. En efecto, que dicho reino sea un ideal no significa que no podría darse en la vida real, puesto que si no pudiera darse en la vida real no tendríamos deber de obrar de acuerdo con el ideal. Que tal reino sea un ideal significa que obrar según el ideal es una tarea permanente o infinita que no implica un último término, ya que un ideal no es un producto acabado o una institución establecida.

\section{Finalidad y juicio reflexivo en la fórmula de la humanidad}

En este apartado examinaré la segunda formulación de la ley moral presentada en la Fundamentación de la metafísica de las costumbres, destacando sus aspectos de finalidad y la intervención del juicio reflexivo. En efecto, si se quiere dar acceso a la ley moral acercándola a la intuición en cuanto ello es posible, se ha de proceder mediante el juicio reflexivo. ${ }^{17}$ Por último, me ocuparé de la deliberación moral como un elemento crucial de la ética kantiana y procuraré hacer ver que dicha deliberación requiere que el sujeto trabaje en la maduración reflexiva de las máximas.

Muchos asocian la ética de Kant con la fórmula de la universalidad de las máximas; sin embargo, cuando Kant señala nuestros deberes éticos con-

15 Al respecto pueden consultarse las obras de Javier Muguerza, Roberto Rodríguez Aramayo, Hannah Arendt, Jorge Dotti, Paul Guyer, Allen Wood y Rudolf Makkreel, quienes se han ocupado de esta temática.

16 Cfr. Ak., IV, 433-434.

17 Cfr. Ak., IV, 436. 
cretos apela a la fórmula de la humanidad. ${ }^{18}$ Kant alude a infinidad de pormenores al describir dichos deberes y explícitamente enumera catorce. De ellos sólo uno se funda apelando a la fórmula de la universalidad. De los trece restantes, nueve se basan explícitamente en la fórmula de la humanidad y los cuatro últimos se basan, por implicación, en la misma fórmula.

Quizá una buena manera de empezar a revisar la fórmula de la humanidad sea citando aquel pasaje en el que Kant afirma:

Suponiendo que haya algo cuya existencia en sí misma posea un valor absoluto, algo que, como fin en sí mismo, pueda ser fundamento de determinadas leyes, entonces en ello y sólo en ello estaría el fundamento de un posible imperativo categórico, es decir, de la ley práctica. ${ }^{19}$

Puede apreciarse que son tres los rasgos con los que Kant caracteriza el "algo" que está tratando de describir. En primer lugar, se trata de un fin en sí o fin objetivo, i.e., un fin que tiene valor incondicional, que es independiente del deseo y que vale para todo ser racional como motivo que obliga a su voluntad. En efecto, en el pasaje inmediatamente anterior, ${ }^{20}$ Kant distinguió dos tipos de fundamentos por los que actúa la voluntad: a) el incentivo (Triebfeder) o fundamento subjetivo es una cosa agradable que se espera obtener mediante un esfuerzo o trabajo y anima a realizar éste. Así pues, se trata de un fin basado en un deseo empírico de un objeto; b) el motivo (bewegungsgrund) o fundamento objetivo es un fin dado por la razón y válido para todo ser racional. Lo más importante que dice Kant aquí es que un motivo siempre ha de ser un fin (Zweck) y que toda acción "contiene" un fin, i.e., no hay acción alguna hecha sin tener en vista un fin. ${ }^{21}$ Así pues, una voluntad racional puede ser motivada para obedecer un imperativo categórico sólo por un tipo determinado de fin, a saber, un fin en sí mismo. En efecto, lo opuesto a un fin en sí mismo sería un fin relativo, i.e., un fin con un valor condicionado o dependiente de la constitución subjetiva de cada ser racional en particualr; este tipo de fin sería sólo un incentivo y daría lugar únicamente a imperativos hipotéticos. En este sentido podríamos decir que tanto la forma legislativa de las máximas (principio formal o fórmula de la universalidad) como el motivo del deber (principio material o fórmula de la humanidad) han de estar subordinados a un fin que ha de ser, necesariamente, un fin en sí mismo.

${ }^{18}$ Cfr. Metafísica de las costumbres, Ak, VI, 237, 389, 423, 425, 427, 429, 432, 436, 437$440,442-444,446-447,451,453,454,456,458-462,465-467$.

19 Cfr. Ak, IV, 428.

20 Cfr. Fundamentación..., Ak., IV, 427.

21 Véase también Metafísica de las costumbres, Doctrina de la virtud, Ak, VI, 385. 
En segundo lugar, se trata de un fin existente o autosuficiente. Kant nos hace ver que fin no necesariamente es algo que aún no existe; él distingue entre fin existente y fin que ha de realizarse, ${ }^{22}$ i.e., aquel estado de cosas que no existe aún pero que llegará a existir mediante la causalidad (el esfuerzo o el trabajo) de un agente. Kant designa con el término "fin" aquello por motivo del cual actuamos, o nos refrenamos de actuar, y cuyo valor proporciona un término en la serie de razones para actuar. ${ }^{23}$ Esta descripción es adecuada tanto para los fines que han de realizarse como para las cosas existentes en consideración de las cuales actuamos. Kant introduce en la fórmula de la humanidad el concepto de fin existente, i.e., de algo que ya existe, cuya existencia es en sí misma un fin y que tiene valor capaz de motivarnos a actuar. Según él, actuar por deber significa actuar considerando o apreciando el valor humano que cada persona tiene como fin existente o fin en sí mismo. ${ }^{24}$ Aplicando la segunda formulación del imperativo categórico, considerariamos toda acción desde el aspecto de lo que ella expresa o manifiesta respecto de la valoración del agente en torno a lo humano. Así, una conducta sería moralmente buena si manifiesta respeto o estima por la humanidad como fin existente; una conducta sería moralmente mala si expresa falta de respeto o estima ante este valor.

En tercer lugar, se trata de un fin con valor absoluto . o, como Kant dice, con dignidad. Así como en los dos aspectos anteriores Kant estableció un contraste (fin objetivo-fin subjetivo y fin existente-fin que ha de realizarse, respectivamente, para el primero y segundo casos), así también en este tercer aspecto Kant establecerá un contraste entre valor absoluto y valor relativo, i.e., entre dignidad y precio. Un fin con valor absoluto o dignidad es un fin cuyo valor no puede ser comparado, reemplazado o compensado con ningún otro valor. Es un valor que no puede ser medido con otras cosas valiosas ni ser sacrificado razonablemente con el fin de alcanzar otro valor. Pasaremos ahora a examinar en qué puede radicar este valor absoluto.

Según hemos visto, Kant rechaza que los principios morales puedan fundamentarse en la representación de un fin que ha de realizarse. Para él, sólo un fin existente es capaz de determinar a la voluntad a observar la ley moral, y tal fin es el valor de la humanidad como fin en sí mismo. Para Kant, este valor debe ser visto como el valor que fundamenta la autonomía, en el

22 Cfr. Fundamentación. ., Ak., IV, 437.

23 Cfr. el excelente trabajo de Allen Wood, op. cit., p. 304.

24 En la Metafísica de las costumbres, $A k$, VI, 380, Kant se refiere a este fin independiente como un fin que tendría un papel negativo, i.e., algo en contra de lo cual nunca se debería actuar; es más, la virtud consistiría, precisamente, en nunca actuar contra tal fin. Al respecto puede confrontarse la $K p V, A K, V, 84-89$. Para Kant este fin existente o independiente es la humanidad o la naturaleza racional. Así, actuar por el deber equivale a actuar considerando a la humanidad como fin incondicionado. 
sentido de que es la motivación para actuar autónoma o moralmente. Así, hemos de revisar este concepto de dignidad como conexión entre autonomía y moralidad desde la perspectiva de la fórmula de la humanidad.

Para Kant el concepto de lo "bueno" es, según vimos en la segunda sección de este trabajo, un concepto racional, i.e., determinado o establecido por la razón. A la inversa, podría decirse que si un fin es juzgado bueno habrá de proporcionarnos razones para la acción que serán aplicables a todo ser racional. ${ }^{25} \mathrm{Si}$ el fin de un individuo no puede ser compartido por los demás, no es bueno en sentido moral y la acción no es total o perfectamente racional. Teniendo en mente lo dicho al hablar de los tres grados de racionalidad, podría afirmarse que si hay acciones cuyo grado de racionalidad no es superable, deberá haber fines objetivamente buenos. Como se dijo en ese punto, sólo si hay imperativos categóricos, habrá acciones perfectamente racionales. Ahora agregaremos que si hay acciones perfectamente racionales deberá haber fines objetivamente buenos, i.e., fines cuya existencia pueda ser justificada por la razón. ${ }^{26}$ En resumen, lo que Kant intenta probar es que existe un fin incondicionado y que éste es la humanidad. En efecto, si existe un fin necesario, entonces existe un imperativo categórico, y si existe este último, entonces hay acciones necesarias. ${ }^{27}$

En diversos lugares del Corpus kantiano se aborda la cuestión de qué debe entenderse por "humanidad" cuando se dice de ésta que es un fin en sí mismo. ${ }^{28}$ En tales fragmentos Kant distingue las tres disposiciones originales pertenecientes a la naturaleza, i.e., la animalidad, la humanidad y la personalidad. El término "humanidad" se refiere a la capacidad de fijar fines en general, elegir y organizar los medios conducentes a ellos y combinar todo esto en una concepción de nuestro bienestar en general. En este sentido, el término "humanidad" puede intercambiarse por el de "naturaleza racional". En efecto, el rasgo distintivo de la humanidad como tal es la capacidad de la razón por tomar interés en algo. En otras palabras:

$25 C f r ., K p V, A k$, V, 60-61. Véase también el pasaje inmediatamente anterior donde Kant afirma que "nada queremos por indicación de la razón sino en cuanto lo tenemos por bueno (gut) o malo (böse)". Hay una idea similar en la Fundamentación..., Ak, IV, 412, donde Kant establece que "la voluntad es una facultad de no elegir nada más que aquello que la razón, independientemente de la inclinación, conoce como prácticamente necesario, es decir, 'bueno'". Por último, quiero referirme a un pasaje más de la $K p V, A k, V, 62$, donde se sostiene que "si un fin fuera establecido por la inclinación y la razón sólo determinaría los medios para alcanzarlo, entonces sólo los medios podrían llamarse 'buenos'".

26 Cfr., KpV, Ak., V, 62.

27 Cfr. Metafísica de las costumbres, Doctrina de la virtud, Ak, VI, 385.

28 Cfr. Antropología en sentido pragmático, Ak., VII, 322-324; Crítica del juicio, Ak., V, 426427; La religión en los límites de la mera razón, Ak, VI, 26; Fundamentación de la metafísica de las costumbres, Ak., IV, 392, 437-440. 
la capacidad de decidir, bajo la influencia de la razón, que algo es deseable o valioso y que merece ser perseguido o realizado. Esto equivale a juzgar algo como importante o valioso no porque contribuya a la satisfacción de los instintos, sino en razón de su propia conveniencia. Por otra parte, Kant usa el término "personalidad" para referirse a uno de los aspectos o funciones de la capacidad racional, i.e., la de respetar la ley moral y actuar teniendo el deber, o la ley moral, como único motivo suficiente para determinar la voluntad. ${ }^{29}$ Para Kant el valor absoluto o dignidad de la naturaleza racional radica en la humanidad y no en la personalidad. ${ }^{30}$ En efecto, si el imperativo categórico ha de obligar a todo ser racional, el fin que lo fundamenta no puede tener una existencia contingente como sucedería si tal fin radicara sólo en las personas de buena voluntad, i.e., que respetan la ley moral. ${ }^{31}$

Kant sostiene que sólo hay una cosa que satisface el concepto de fin en sí mismo, existente y con valor absoluto, a saber, la naturaleza humana o naturaleza racional. Kant afirma explícitamente que el valor absoluto de la naturaleza racional puede establecerse a partir de que es el sujeto de todos los fines:

La naturaleza racional se distingue de las demás porque se pone a sí misma como fin $[\ldots]$ contra del cual nunca se debe actuar y que no debe apreciarse nunca como mero medio sino siempre como fin de todo querer. Este fin no puede ser otro que el sujeto de todos los fines posibles, pues éste es, al mismo tiempo, el sujeto de una posible voluntad absolutamente buena. Por lo tanto, el principio "obra respecto de todo ser racional de modo tal que tu máxima valga como fin en si" es idéntico al principio "obra según una máxima que contenga en sí su validez universal para todo ser racional. Esto equivale a que el sujeto de los fines, i.e., el ser racional mismo no debe nunca ponerse por fundamento de las acciones como simple medio sino como suprema condición limitativa en el uso de todos los medios". 32

29 Humanidad es la capacidad de determinación racional de fines en general; personalidad es la capacidad de adoptar fines moralmente obligatorios. Tratar a la humanidad como fin en sí misma nos llevará inevitablemente a la realización de la personalidad. Incluso se podría decir que personalidad y humanidad completa o perfecta son la misma cosa. Al respecto, véase Ch. Korsgaard, op. cit., pp. 186-187.

30 Hay que destacar que la libertad humana se realiza en la adopción de la humanidad como fin en sí misma. En efecto, si un fin es un objeto de libre elección, la única cosa a la que otro no puede obligarnos es a adoptar un fin determinado; al respecto puede verse Metafísica de las costumbres, Doctrina de la virtud, $A k$, VI, 381 y 384 .

31 No voy a entrar aquí en la interesante cuestión de las relaciones entre humanidad y personalidad, racionalidad y moralidad; ello ameritaría un cuidadoso estudio; al respecto pueden sernos de mucha utilidad los trabajos ya mencionados de Christine $M$. Korsgaard y Stephen $\mathrm{H}$. Watson.

32 Cfr: Fundamentación. .., Ak., IV, 436-437. 
En Probable inicio de la historia humana, ${ }^{33}$ Kant describe imaginariamente cómo pudo el hombre ir dejando la conducta de los instintos animales y empezar a hacer uso de la razón y a fijar fines. El resultado de esto fue que el ser humano "llegó a entender, si bien oscuramente, que él es el verdadero fin de la naturaleza, y a afirmarse como un fin en sí mismo que ha de estimarse como tal por los demás y que no ha de usarse meramente como un medio para otros fines".

Un pensamiento similar es el que se expresa en la Crítica del juicio, donde el rango o estatuto de los seres racionales como fin último de la naturaleza se infiere de su capacidad reflexiva de concebir fines y organizarlos en un sistema:

El ser humano es el fin último de la creación aquí en la tierra porque es el único ser sobre la tierra que puede formar el concepto de fines y usar la razón agregando un propósito estructurado de las cosas en un sistema de fines. ${ }^{34}$

Por último, deseo citar un pasaje más de la Crítica del juicio en apoyo de mi tesis:

Pero si las cosas del mundo, en cuanto seres dependientes en su existencia, requieren de una causa suprema que actúa con arreglo a fines, el hombre entonces es causa final de la creación; pues sin éste la cadena de los fines subordinados unos a otros no estaría completamente fundada, y únicamente en el hombre, aunque en él sólo como sujeto de la moralidad, puede encontrarse la legislación incondicionada en vista de los fines, la única, pues, que lo capacita para ser un fin final al cual toda la naturaleza está teleológicamente subordinada. ${ }^{35}$

La mención del juicio reflexivo en el terreno moral es totalmente explícita en el siguiente pasaje:

Hemos mostrado en lo precedente que tenemos razón suficiente para juzgar al hombre [...] como fin último de la naturaleza aquí en la tierra, en referencia al cual todas las demás cosas naturales constituyen sistemas de fines, según principios de la razón, y no por cierto para la facultad del juzgar determinante, pero sí para la reflexionante. ${ }^{36}$

Así pues, Kant parte del valor que le damos a los fines que establecemos y de ahí se remonta, mediante un "regreso a las condiciones", a la fuente u

${ }^{33}$ Cfr. Fundamentación..., Ak., VIII, 114.

${ }^{34}$ Cfr. Crítica del juicio, Ak, V, 427.

35 Cfr. Crítica del juicio, Ak, V, 399.

${ }^{36}$ Cfr. Crítica del juicio, Ak, V, 388. Las citas de estos dos últimos pasajes son de la excelente traducción: Crítica de la facultad de juzgar, Pablo Oyarzún, Monte Ávila Editores, Venezuela, 1992, pp. 362 y 356, respectivamente. 
origen que funda tal valor, i.e., la naturaleza racional del ser que establece el fin. Puesto que la naturaleza racional es la fuente de todos los valores, se considera fin en sí misma y valiosa absoluta e incondicionalmente.

Ciertamente, la argumentación de Kant, en las dos primeras secciones de la Fundamentación. . . , depende de la aplicación de la distinción condicionado-condición al concepto de lo bueno. En efecto, en la búsqueda de las condiciones, la razón no cesa hasta encontrar la condición incondicionada. Éste es un método que Kant califica de "analítico" o "regresivo"37 y en el cual algo es dado y se procede a buscar las condiciones que lo hacen posible. Se comienza con lo dado en la experiencia, en este caso, el conocimiento ordinario o común de la moralidad. El punto de partida es algo ya conocido como verdadero y seguro y nos permite remontarnos o "regresar" hasta las fuentes $\mathrm{u}$ orígenes aún no conocidos y sin los cuales no sería posible tener tal experiencia. Así, la Fundamentación... nos proporciona un análisis de la conciencia moral ordinaria que tiene como punto de partida los juicios morales comunes y el sentimiento de la obligatoriedad del deber y que busca poner de manifiesto los orígenes de tales juicios. Aceptando que hay un imperativo categórico y que, por ende, hay también acciones perfectamente racionales, se plantea entonces la pregunta de qué es lo que hace posible que se dé este tipo de acciones. Trasladando este cuestionamiento a la segunda fórmula del imperativo categórico, la pregunta equivaldría a qué es aquello capaz de justificar totalmente un fin, i.e., en qué puede consistir un bien incondicional.

De alguna manera la pregunta ya fue contestada en la primera frase de la Fundamentación... , cuando Kant afirma que la única cosa que puede concebirse como absolutamente buena es la buena voluntad. Sin embargo, la argumentación que Kant nos ofrece puede ayudarnos mostrándonos qué ha de ser la buena voluntad y cómo desempeña el papel de condición incondicionada. Antes de revisar tal argumentación, Kant elucida su tesis explicando los dos siguientes puntos. En primer lugar, la buena voluntad es la única cosa que tiene valor intrínseco absoluto ${ }^{38}$ que no depende de las circunstancias o de la utilidad o esterilidad al alcanzar sus resultados; en segundo lugar, el valor de todo lo demás es dependiente y condicional de este valor absoluto. Por ello, la buena voluntad es la condición incondicionada de la bondad de todas las demás cosas. ${ }^{39}$

37 Cfr. Prolegómenos, Ak., IV, 276 n.

38 Cfr. Fundamentación. .., Ak., IV, 394.

39 Es claro que con esto Kant no está diciendo que la buena voluntad sea la única cosa valiosa como fin. Obviamente, los medios son condicionalmente buenos y su bondad depende de la bondad de los fines de los cuales ellos son instrumentos. Incluso la felicidad, la cual sin duda es un fin, es condicionalmente buena y su valor depende de la buena voluntad. Por 
Creo que ya estamos en condiciones de examinar la argumentación que Kant nos ofrece. La razón práctica, al igual que la razón especulativa, busca la condición incondicionada. Sin embargo, hay una diferencia entre ambas. En efecto, la clase de explicación incondicional que podria satisfacer a la razón especulativa no es una explicación que pueda alcanzar la razón. Así, la "pasión" especulativa de la razón está condenada a permanecer insatisfecha. La razón práctica, en cambio, no está sujeta a tal tipo de restricción, pues la humanidad puede ser considerada como algo incondicionalmente bueno y como fuente $\mathrm{u}$ origen de la justificación de todas las demás cosas que sólo son condicionalmente buenas. Así pues, Kant hace un "regreso" a lo incondicionado y afirma:

todos los objetos de las inclinaciones tienen sólo un valor condicionado; pues si no hubiera inclinaciones y necesidades fundadas sobre las inclinaciones, su objeto carecería de valor. Pero las inclinaciones mismas, como fuentes de las necesidades, están tan lejos de tener un valor absoluto para desearlas, que más bien debe ser el deseo general de todo ser racional librarse enteramente de ellas. Así pues, el valor de todos los objetos que podemos obtener por medio de nuestras acciones es siempre condicionado. Los seres cuya existencia no descansa en nuestra voluntad, sino en la naturaleza, tienen, empero, si son seres irracionales, un valor meramente relativo, como medios, y por eso se llaman cosas; en cambio, los seres racionales llámanse personas porque su naturaleza los distingue ya como fines en sí mismos, esto es, como algo que no puede ser usado meramente como medio, y, por lo tanto, limita en ese sentido todo capricho y es un objeto de respeto. Éstos no son, pues, meros fines subjetivos, cuya existencia, como efecto de nuestra acción, tiene un valor para nosotros, sino que son fines objetivos, esto es, cosas cuya existencia es en sí misma un fin, y un fin tal, que en su lugar no puede ponerse ningún otro fin para el cual debieran ellas servir de medios, porque sin esto no hubiera posibilidad de hallar en parte alguna nada con valor absoluto; mas si todo valor fuera condicionado y, por tanto, contingente, no podría encontrarse para la razón ningún principio práctico supremo. ${ }^{40}$

He querido citar íntegramente este pasaje así como el siguiente, pues en ellos se subraya la tesis de que la naturaleza racional en sí misma es un fin objetivo:

supuesto, es una gran tentación pensar que la propia felicidad es incondicionalmente buena. La buena voluntad no es ni el único bien ni el bien total; pero sí es el bien supremo, i.e., es la condición de cualquier otro bien, incluso del deseo de felicidad. Esto significa que para hablar de bien perfecto o total, además de la virtud se requiere de la felicidad. Sin embargo, la virtud es la condición indispensable que nos hace dignos de ser felices. $C f r . K p V, A k$., V, 110; Fundamentación..., Ak., IV, 396.

40 Cfr. Fundamentación..., Ak, IV, 428. 
lo que es fin para todos necesariamente porque es fin en sí mismo, constituye un principio objetivo de la voluntad y, por lo tanto, puede servir de ley práctica universal. El fundamento de este principio es: la naturaleza racional existe como fin en sí misma [...] del cual, como fundamento práctico supremo, han de poder derivarse todas las leyes de la voluntad. ${ }^{41}$

Cuando establecemos un fin, le atribuimos bondad o valor objetivo en el sentido de que el bien es representado por la razón como prácticamente necesario. ${ }^{42}$ Esto no significa que toda bondad sea solamente subjetiva. Al contrario, que la elección racional de los fines es el acto por el cual la bondad objetiva entra al mundo; y el hecho de que la naturaleza racional sirva como fuente de tales valores implica que ella tiene valor objetivo como fin en sí misma. Por otra parte, esto no significa que la autonomía de la voluntad no pueda ser conciliada con la objetividad del valor; en efecto, el único objeto de valor que no es establecido como tal por la voluntad, es el valor absoluto de la voluntad misma como único fundamento necesario de todo valor objetivo.

Para Kant, la objetividad de las prescripciones de la voluntad procede de la capacidad racional para establecer leyes objetivas y fijar fines con valor objetivo. Si la naturaleza racional es la fuente que prescribe toda bondad objetiva, ha de ser el objeto más fundamental de estima y respeto, puesto que si no fuera respetada como objetivamenta buena, ninguna otra cosa podría ser considerada objetivamente buena.

En el regreso a la condición incondicionada hemos llegado a la naturaleza racional como facultad de establecer fines al conferir a éstos bondad. Hemos visto que para desempeñar este papel la naturaleza humana debe ser algo de valor incondicional y debe ser un fin en sí misma. ${ }^{43}$ De esto se sigue que una acción que viola el rango de fin en sí mismo de la naturaleza racional no puede ser una acción racional. En otras palabras, actuar contra este fin incondicional implica caer en contradición. En suma: la naturaleza racional es el límite o condición última de la racionalidad de las acciones.

Podríamos concluir este apartado describiendo las éticas deontológicas como éticas que representan el cumplimiento del deber como la obediencia a una norma obligatoria. Si incluimos única y exclusivamente la fórmula de la universalidad, la ética de Kant correspondería a esta descripción. Pero si tenemos en mente la fórmula de la humaidad, no podríamos decir que

41 Cfr. Fundamentación..., Ak., IV, 429.

42 Cfr. Fundamentación..., Ak, IV, 412.

43 No quiero dejar de señalar que el valor absoluto de la naruraleza racional implica que todos los seres humanos tienen el mismo valor sin importar nada, incluso si son moralmente buenos o malos. No hay algunos seres racionales más valiosos que otros. Por supuesto, esto no quiere decir que todo ser racional habrá de recibir idéntico trato en cualquier aspecto concreto. 
la ética kantiana sea deontológica. En efecto, según esta última fórmula, el cumplimiento del deber no es una regla que deba ser obedecida; se trata, más bien, del valor que funda las reglas morales y que proporciona el motivo racional para obedecerlas. Lo que aquí se prescribe es que nuestras acciones manifiesten el respeto debido al valor de lo humano.

Así pues, la pregunta que se ve venir es la de cómo podemos saber si la naturaleza de una acción es compatible con la fórmula de la humanidad, es decir, con la consideración del valor absoluto del ser humano. Esta cuestión de deliberación apela claramente al juicio reflexivo y de ello nos ocuparemos en el próximo apartado final.

\section{Conclusiones}

Contrariamente a lo que podría pensarse, la pregunta anterior no es una pregunta irrelevante, pues de hecho existen polémicas y cuestionamientos serios acerca de si una acción expresa respeto o falta de respeto a la humanidad. Considero que el problema no radica en el significado de la fórmula de la humanidad, pues éste es claro y bien definido. La dificultad estriba, más bien, en la aplicación de la fórmula. En efecto, en la liberación moral intervienen datos que no siempre nos parecen vinculados lógicamente de manera directa con la naturaleza racional y que, por ende, no parecen ser parte del significado mismo de la fórmula de la humanidad. Sin embargo, creo que el argumento que Kant ha manejado nos enseña cómo aplicar la fórmula de la humanidad y qué es lo que significa tratar a la humanidad como fin en sí misma. De no ser así, tendría que concluir diciendo que la fórmula de la humanidad carece de contenido moral y es incapaz de resolver por sí misma las cuestiones morales relevantes a las cuales se pretende aplicar.

Sin duda, nuestro concepto de naturaleza racional es corregible y, por ello, variable. No obstante, gracias a las diversas ciencias y disciplinas podemos disponer de un conjunto de conocimientos en torno a la naturaleza racional que guía nuestros juicios sobre su valor y sobre cómo ha de expresarse el respeto a dicho valor, y tales conocimientos no son prejuicios irracionales. La postura de Kant, como yo la entiendo, nos permitirá sostener que nuestro conocimiento sobre la naturaleza racional avanza, se completa y perfecciona en la medida que se enriquece socio-históricamente el contenido de la fórmula de la humanidad. En efecto, "tomar al hombre como fin en sí mismo y no sólo como medio" no significará lo mismo hoy que en el siglo xvir. Así, algunas formas de desigualdad social, política y económica nos parecen hoy en día muy cuestionables o incluso incompatibles con la fórmula de la humanidad, e.g., la exclusión de una gran mayoría de la sociedad del derecho al voto, o a ocupar un cargo público, o bien la 
autoridad del varón sobre los miembros de su familia o la exclusión de la mujer de los procesos educativos, etcétera.

Un ejemplo del avance y perfeccionamiento de nuestro conocimiento sobre la naturaleza racional lo tenemos en cómo hoy en día más y más personas empiezan a considerar su participación en el sistema político y económico como una función inherente o esencial de su obrar racional, por lo cual empieza a ser más y más difícil considerar tal exclusión como algo que no sea sino una faita de respeto al valor humano de los excluidos. Considero que en este avance juega un papel importante la educación.

En efecto, para Kant la educación ha de promover el perfeccionamiento de toda la especie humana; ${ }^{44}$ debe intentar establecer y promover un nuevo orden social, i.e., una "república cosmopolita" en la que reine la paz perpetua y en la que los hombres puedan alcanzar las perfecciones naturales y morales que les corresponden; si la educación fuera imbuir en el individuo normas prácticas, no pasaría de ser un simple amaestramiento. En cambio, se trata de algo distinto, cuando la educación es la orientación reflexiva en torno a los principios directivos o máximas, pues esto sí permite una autodeterminación racional.

He querido examinar la fórmula de la humanidad, pues considero que en ella puede apreciarse, con más claridad que en la fórmula de la universalidad, que el examen al que se han de someter las máximas para probar su moralidad es una reflexión racional elaborada mediante juicios reflexivos. Para terminar, me resta sólo revisar los cuatro ejemplos con los que Kant ilustra la aplicación de la fórmula de la humanidad. Hablando con precisión, los ejemplos son negativos, i.e., prohibiciones que ilustran la no aplicabilidad de la fórmula: ${ }^{45}$ el suicidio, la falsa promesa, el descuido del desarrollo de los propios talentos y la indiferencia ante la necesidad ajena.

Para el primer caso, quiero citar el pasaje que sirve de epígrafe a este trabajo, pues considero que Kant no podía ser más taxativo al señalar que:

el sujeto de una posible voluntad absolutamente buena $[\ldots]$ no puede, sin contradicción, posponerse a ningún otro objeto. ${ }^{46}$

En otras palabras, cuando en una acción se busca la obtención de un fin que implica relegar, posponer o incluso desechar la naturaleza racional, tal acción resulta contradictoria o absurda. En efecto, no es posible perseguir

44 Cfr. Immanuel Kant über Padägogik, Ak., IX, 448 ss.

45 Deseo subrayar que éstos son cuatro ejemplos de no aplicabilidad de la fórmula de la humanidad y que esto no debe confundirse con la fundamentación de nuestros deberes éticos sobre la base de dicha fórmula. Al respecto véase la $\mathrm{n}$. 18 de este trabajo.

46 Cfr. Fundamentación. ., Ak., IV, 437. 
un bien relativo, considerándolo mejor o más importante que la naturaleza racional, sin caer en una forma de contradicción. Anular la naturaleza racional equivale a destruir la fuente de bondad de todos los demás fines relativos, por lo cual no es posible negar aquélla y continuar afirmando estos últimos.

En el sugundo ejemplo, la fórmula de la humanidad nos hace ver que el deseo de escapar de un apuro económico no puede ser una razón suficiente (es decir, que pueda justificar) para hacer una promesa falsa. De ser una razón suficiente, todos podrían prometer en falso; pero ésto haría que mi falsa promesa no "sirviera" para sacarme del apuro económico. En efecto, si mi falsa promesa "funciona" es porque cuento, abusivamente, con la veracidad de los demás. En otras palabras, para salir del apuro económico quiero que valga la norma de no prometer en falso y que todo mundo la observe, porque de lo contrario se daría al traste con mi propósito, pero yo pretendo, tramposamente, que tal regla no rija para mí. Es claro que sólo contradiciéndome puedo intentar servirme, como mero medio, de la buena voluntad y de la veracidad los demás.

En los dos últimos ejemplos, la prohibición de descuidar el desarrollo de los propios talentos y de la indiferencia ante la necesidad ajena, se trata de cuidar y promover las capacidades y talentos que nos permiten ejercitar y realizar plenamente nuestro poder de elección racional; es claro que en tales ejemplos se reclama el reconocimiento del valor incondicionado de la naturaleza racional entendida como la capacidad de establecer fines confiriéndoles bondad objetiva. Aquí el deber no es menos obligatorio que en los dos casos anteriores; la única diferencia es que se permite relativizar un área de aplicación, en favor de otras, a causa de la limitación de las posibilidades.

En la última sección de la tercera Crítica, Kant se ocupa de determinar qué es lo que puede desempeñar adecuadamente el papel de propósito final de la creación, si es que consideramos a la naturaleza como un sistema teleológico. Para establecer cuál es la razón de la existencia de la naturaleza misma, Kant se vale del método regresivo que hemos esbozado anteriormente y de la capacidad del juicio reflexivo. En este "regreso" busca aquel propósito que no necesita ya de ninguna condición de posibilidad pues es el propósito último hacia el cual toda la naturaleza está organizada. ${ }^{47}$ Agregaremos ahora que para Kant el último propósito de la naturaleza es la cultura entendida como desarrollo moral de la humanidad. ${ }^{48}$ Esto nos lleva a la tercera formulación del imperativo categórico y a las doctrinas de filosofía política y filosofía de la historia que Kant nos ofrece. Obviamente,

47 Cfr. supra, n. 24, donde hemos visto que el ser humano es el fin último de la creación.

48 Cfr. Crítica del juicio, Ak, V, 433-436; 434 n. y 442-443. 
examinar estas tesis daría lugar a un pormenorizado trabajo que rebasa los propósitos del presente.

Deseo concluir contrastando la facultad de juzgar reflexiva teórica y la facultad de juzgar reflexiva práctica:

Para la facultad de juzgar reflexiva teórica, la teleología física probó con suficiencia, a partir de los fines de la naturaleza, una causa inteligente del mundo; para la facultad de juzgar reflexiva práctica, la teleología moral realiza esto mismo a través del concepto de un fin final, que ella está forzada a atribuir a la creación con propósito práctico. ${ }^{49}$ 